\title{
Rapid morphological change in black rats (Rattus rattus) after an island introduction
}

Oliver R. W. Pergams, David W. Byrn, Kashawneda L. Y. Lee, Racheal Jackson

Rapid morphological change has been shown in rodent populations on islands, including endemic deer mice (Peromyscus maniculatus subspp.) on the California Channel Islands. Surprisingly most of these changes were towards smaller size. Black rats were introduced to Anacapa Island in the mid-1800s (probably in 1853) and eradicated 2001-2002. To assess possible changes in these introduced rats since introduction, eleven cranial and four standard external measurements were taken from 59 Rattus rattus specimens collected 1940-2000. All rat cranial traits changed 3.06-10.43\% (724-2567 d, 0.06-0.42 h), and all became larger. When considered in haldanes these changes are among the fastest on record in any organism, and far exceed changes found in other island rodents. These changes were confirmed by MANOVA (Wilk's $\lambda<0.0005, F_{\text {d.f.15 }}=2974.386, P<0.0005$ ), and all 11 cranial traits significantly fit linear regressions. We speculate that concurrent changes in mice may have been due in part to competition with and/or predation by rats. Future research might evaluate whether the vector of mouse evolution on Anacapa is again changing after rat eradication. 
1 Running heading: Rapid change in rats after an island introduction

2 Title: Rapid morphological change in black rats (Rattus rattus) after an island introduction

3 Names of authors:

4 Oliver R. W. Pergams*, David Byrn, Kashawneda L. Y. Lee, and Racheal Jackson

5 Affiliations of authors:

6 Olive-Harvey College, One of the City Colleges of Chicago, Dept. of Biology, 10001 S.

$7 \quad$ Woodlawn Ave., Chicago, IL 60628 USA (OP, DB, KL, RJ)

8 University of Illinois at Chicago, Dept. of Biological Sciences (MC 066), 845 W. Taylor St.,

9 Chicago, IL 60607 USA (OP)

10 Contact information:

11 Dr. Oliver Pergams, Olive-Harvey College, One of the City Colleges of Chicago, Dept. of

12 Biology, 10001 S. Woodlawn Ave., Chicago, IL 60628. opergams@,ccc.edu, 1.773.291.6502.

13 Rapid morphological change has been shown in rodent populations on islands, including endemic

14 deer mice (Peromyscus maniculatus subspp.) on the California Channel Islands. Surprisingly

15 most of these changes were towards smaller size. Black rats were introduced to Anacapa Island in

16 the mid-1800s (probably in 1853) and eradicated 2001-2002. To assess possible changes in these

17 introduced rats since introduction, eleven cranial and four standard external measurements were

18 taken from 59 Rattus rattus specimens collected 1940-2000. All rat cranial traits changed 3.06- 
$19 \quad 10.43 \%(724-2567 d, 0.06-0.42 h)$, and all became larger. When considered in haldanes these

20 changes are among the fastest on record in any organism, and far exceed changes found in other

21 island rodents. These changes were confirmed by MANOVA (Wilk's $\lambda<0.0005, F_{d . f .15}=$

22 2974.386, $P<0.0005)$, and all 11 cranial traits significantly fit linear regressions. We speculate

23 that concurrent changes in mice may have been due in part to competition with and/or predation

24 by rats. Future research might evaluate whether the vector of mouse evolution on Anacapa is

25 again changing after rat eradication.

26 Keywords: Anacapa Island, California Channel Islands, coevolution, invasive species, island

27 evolution, microevolution, morphology, Peromyscus maniculatus anacapae, rapid evolution,

28 Rattus rattus 

discussion in terms of generations is more useful). Usually the evolution documented is of the introduced organism itself to its new environment, but sometimes rapid evolutionary response of endemic organisms in reaction to an introduction is also shown (Hendry \& Kinnison,1999;

Pergams \& Kareiva, 2009). Introduction (of invasive species and populations) is the most commonly discussed factor in rodent rapid evolution (Berry, 1964; Patton et al., 1975; Pergams \& Ashley, 2001; Pergams et. al., 2003; Pergams \& Lacy, 2007; Pergams \& Kareiva, 2009).

Some of the first recognized examples of microevolution came from studies of island rodents (e.g., Clarke, 1904, Huxley, 1942). An increase in body size is often documented and usually attributed to release of mainland selective pressures (Case, 1978; Foster, 1964; Lawlor, 1982). In a study of tri-colored squirrels in Malaysia, Indonesia, and Thailand, Heaney (1978) shows an inverse correlation of body size with island area up to about $100 \mathrm{~km}^{2}$, above which body size increases. Lomolino (1985) shows that trends in body size associated with islands were tied to the animals' absolute size: larger mammals tend to become smaller on islands and smaller mammals tend to become larger.

Comparing cranial and skeletal traits as well as body size, Pergams \& Ashley (2001) perform a meta-analysis of rapid morphological change in island rodents: in Mus musculus after introduction to islands of the North Atlantic (Berry, 1964, Berry et al., 1978); in Rattus rattus after introduction to the Galapagos Islands (Patton et al. 1975); and in Peromyscus maniculatus on the California Channel Islands (Pergams \& Ashley, 1999, 2000). The authors confirm that microevolution of both gross body size and cranial and skeletal traits are greater on smaller and more remote islands. Millien \& Damuth (2004) and Millien (2006, 2011) suggest that island populations exhibit larger body sizes not because they are evolving toward gigantism, but 
52 because their evolution toward smaller size (due to climate warming; Mayr, 1963; Smith et al., 53 1995) has merely been slowed. endemic subspecies of deer mouse, Peromyscus maniculatus. The land vertebrate fauna of the

Materials and Methods

Channel Islands is depauperate, and deer mice are the only land mammal species endemic to all eight islands. Deer mouse populations reach high densities on several of the islands, probably because there are few predators, and seem to exhibit cyclicity in population size, as do voles and lemmings (Drost \& Fellers, 1991; Pergams et al., 2000).

Endemic mice on Anacapa Island (Peromyscus maniculatus anacapae) were found to have mostly become smaller (including in body size) between 1940 and 1978, except their noses became broader and their ears became larger (Pergams \& Ashley, 1999, 2000). These trends are not matched in the other two California Channel Islands evaluated, Santa Barbara and Santa Cruz. Also, there is no record of black rats on either island. The authors suggest responses on Anacapa may be due to the presence of rats.

Black rats (Rattus rattus) were likely introduced to the California Channel Islands during the mid- to late 1800s (Collins et al., 1979), probably in 1853 with the shipwreck of the $S S$ Winfield Scott on Middle Anacapa islet. The ship was a sidewheel steamer that transported passengers and cargo between San Francisco, California and Panama in the early 1850s, during the California Gold Rush (Gleason, 1958). Though mice on Anacapa have been evaluated for rapid change as above, rats on Anacapa have not. Our prediction is that rats will have become larger over time, due to reduced predators and release of selective pressures. 
Museum, the Natural History Museum of Los Angeles County, and specimens from the NGO

Island Conservation were examined. We received permission from all museums to access the specimens. Two rats were determined to be juvenile by skull suture (DeBlase \& Martin, 1974) and excluded from further analysis. The remaining adult specimens and collection years are as follows: 1940 ( $\mathrm{n}=12), 1975$ (5), 1978 (21), 1979 (9), 1986 (2), and 2000 (10). It was not possible to get more modern mouse specimens: rats were eradicated on Anacapa in 2001-2002 (Howald et al. 2009). Indeed, the ten year 2000 specimens utilized in this study were collected just prior to

the eradication. There were 22 males, 16 females, and 21 unknown.

Eleven cranial measurements were taken following Collins and George (1990, unless otherwise indicated). Measurements included: alimentary toothrow (AL), breadth of braincase (BB), breadth of rostrum (BR), depth of braincase (DBC), greatest length of skull (GL), interorbital breadth (IB), length of braincase (LBC), length of incisive foramen (LIF), length of palate plus incisor (LPN, measured as the greatest distance from the end of the nasals to the mesopterygoid fossa), length from supraorbitals to nasals (ONL, measured as the least distance from the supraorbital notch to the tip of the nasals), and zygomatic breadth (ZB).

Cranial measurements of a total of 59 specimens were taken by DB, RJ, and KL with digital calipers to the nearest $0.5 \mathrm{~mm}$. Each worker measured each trait three times and utilized the mean. A threshold variance $>0.1$ of the three means required re-measuring of that trait. The four standard external measurements in museum specimens were originally made by numerous different museum preparers and recorded from museum tags: total length (TOT), tail length (TAIL), hind foot length (HF), and ear length (EAR). Because of either lack of external measurement by museum preparers or damage to the skulls, some measurements were not 
available for some specimens. In particular, we did not have external measurements for 23 specimens. In 13 cases this was due to skulls resident in museum collections not having external measurements attached. The 10 specimens from Island Conservation were so highly decayed that any external measurements would have been guesswork. In all cases all measurements available to us were used. A spreadsheet containing all measurements may be found online at XXXXXX. We used visual examination of normal probability plots (Afifi et al., 2004) and the Shapiro-Wilk $W$ statistic to test for normality of distribution. Kolmogorov-Smirnov $D$ statistic test was not used because these tests have poor power properties and tend to reject the null hypothesis with large sample size and accept it with small sample size (Afifi \& Clark, 1997).

To evaluate sexual dimorphism, two-sample $t$-tests were performed after dropping 21 specimens of unknown sex (leaving 38 specimens of known sex). Results of $t$-tests were considered significant at the $95 \%$ confidence level. The specimens of unknown sex were included in subsequent analyses.

We used two methods to evaluate changes over time: A) categorical analysis and B) linear regression Because the longest gap between collection years was 35 years, and the next longest gap was only 14 tears, we chose to perform our categorical analysis (MANOVA) on two time periods $=1940 \& 1975-2000$. Also, these categories fit well with when Anacapa deer mice were collected (1940 \& 1978), allowing for more direct comparison. However, damage to specimens and lack of measurements did not permit inclusion of the full multivariate data on many of the specimens. Accordingly, we also performed independent-samples $t$-tests, testing the significance of the difference between the sample means of the pre- and post-1950 time periods of each measurement of all specimens. We used the Levene statistic (Brown \& Forsythe, 1974) to test the assumption of equal variance, and applied the appropriate $t$-test. Though there have been recent 
and substantial objections to the use of sequential Bonferroni corrections [especially by ecologists; Moran, 2003], to be conservative we then applied a Holm-Bonferroni sequential correction to account for the multiple tests being conducted (Holm, 1979). To compare means of non-normally distributed traits, we used Kruskal-Wallis $H$ tests.

Because we wished to evaluate rates of change as well as total amounts of change, we calculated the rate of annual change in each significant trait. This was done by dividing the difference in means by the difference in the means of collection years, both between periods. Darwins were calculated with the equation:

$\mathrm{d}=|(\ln \times 2-\ln \times 1) /(\mathrm{t} 2-\mathrm{t} 1)|$,

where $\ln x 1$ and $\ln x 2$ are sample means of $\ln$ measurements at times $\mathrm{t} 1$ and $\mathrm{t} 2$, respectively (measured in millions of years).

However, evolution calculated in standard deviations per generation (haldanes) has several advantages. Rates in haldanes are independent of dimension in a way that rates in darwins are not, since traits are passed onto progeny only between generations, and generation times vary between organisms by many orders of magnitude. This makes haldanes more readily comparable in terms of quantitative evolutionary genetics (Gingerich, 1993). Haldanes were calculated with the equation:

$\mathrm{h}=|[(\ln \mathrm{x} 2 / \mathrm{s} \ln \mathrm{x})-(\ln \mathrm{x} 1 / \mathrm{s} \ln \mathrm{x})] /(\mathrm{t} 2-\mathrm{t} 1)|$ where $\ln x 1$ and $\ln x 2$ are sample means of $\ln$ measurements at times $t 1$ and $t 2$ respectively (measured in generations), and $\sin \mathrm{x}$ is the pooled standard deviation of $\ln \mathrm{x} 1$ and $\ln \mathrm{x} 2$ (Haldane, 1949). Published demographic data was used to estimate generations per year (Erickson \& Halvorsen, 1990). 
59 specimens). To lessen this effect we performed linear regressions comparing each measurement of each trait, with the year in which the specimen was collected.

Results

Data were first examined for normality of distribution through inspection of normal probability plots (Afifi et al., 2004) and Lilliefors test (SPSS, Inc., 1998). We found all traits except AL to be normally distributed. There was no significant sexual dimorphism for any of the 15 measurements.

Results of Levene's tests, independent samples $t$-tests, and Kruskal-Wallis tests are given in Table 1. In rats, all cranial measurements (but no external measurements) were found to have changed over time. We feel our not finding significant change in external measurements was very likely due to insufficient sample size; missing from 23/59 (39\%) of the specimens. MANOVAs corroborated individual results from the $t$-tests. Rats collected in 1940 were extremely significantly different from rats collected in 1975-2000 (Wilk's $\lambda<0.0005, F_{\text {d.f. } 15}=2974.386, P<$ $0.0005)$.

Table 2 gives amounts and rates of evolutionary change. All rat cranial traits changed 3.06-10.43\% (724-2567 $d, 0.06-0.43 h)$, and all became larger. All external traits also grew larger, but probably because of much smaller sample size, not significantly so.

Table 3 shows the results of our linear regressions. All cranial traits were found to be significant, while none of the external traits were found to be significant. 

in the more accurate haldanes, some of these changes are among the fastest on record (Hendry et al., 2007), the maximum of $0.43 h$ (trait IB) exceeded only by systems such as Trinidadian guppy spot number, spot area, spot length, offspring size, $\&$ size: 0.43-0.74 $h$ (Endler, 1980; Reznick et al., 1997); Galapagos finches weight, bill depth, bill width, bill length, beak size: 0.43-0.71 $h$ : (Grant \& Grant, 1995; Grant, 2002); and freshwater copepod egg type switch date: $0.49 h$ (Hairston \& Walton, 1986). These rates of change in the rats are far above the highs found in other island rodents, including invasive black rats on the Galapagos Islands and endemic deer mice on the California Channel Islands [0.03 $h$ max (Pergams \& Ashley, 2001)].

It is interesting that our linear regressions showed all cranial traits to be significant, and that all cranial traits increased monotonically across the three time periods. Four possible explanations for temporal variation of phenotypic characters are: (1) nongenetic, environmental effects (plasticity); (2) gene flow from morphologically different source populations; (3) stochastic evolutionary change through genetic drift; or (4) response to natural selection. We feel that non-genetic environmental factors such as nutrition or maternal effects are an unlikely explanation for all of the morphological changes observed. First, changes appear so great that some genetic component must be involved. Second, all of the rat's cranial measures increased in size, while at largely the same time most of the mice's traits decreased in size. If environmental plasticity were the cause of the changes we would expect both species' traits to change in the same direction.

Several factors argue against gene flow in the case presented here. First, the rats inhabit oceanic islands separated by at least several kilometers from other islands or from the nearest mainland point. Second, there is no record of rats on nearby islands. 
A third causative factor that merits consideration is genetic drift. Anacapa is quite small (2.9 sq km, all Anacapa islets together), but mice are often extremely abundant. A three to four year population size cycle is thought to exist on Anacapa, but the minimum size is still probably in the thousands (Pergams et al., 2000). A final argument against genetic drift is the observation that in both rats and mice many morphological characters are changing, and in most cases changes are in the same direction. Even if certain characters exhibited higher levels of evolutionary plasticity, genetic drift would not be expected to direct changes in many such characters in a uniform direction.

Over approximately the same time frame that some rat traits were getting bigger, endemic deer mice were mostly getting smaller, except deer mouse ear length and nostral width got bigger (Pergams \& Ashley, 1999, 2000, 2001). The changes in these mice do not seem to be due to climate change or changes in human population density (Pergams \& Lawler, 2009), factors evaluated in that paper. The changes toward smaller size in the mice are also not consistent with release of selective pressures upon introduction.

We speculate that changes towards mostly smaller size in mice may have been driven by competition with and predation by black rats. Collins et. al (1979) study stomach content of both species, and find that both eat at least seven of the same plants: sand lettuce (Dudleya caespitosa), wild cucumber (Echinocystis lobate), coastal prickly pear (Opuntia littoralis), sea fig (Carpobrotus chilensis), iceplant (Carpobrotus edulis), slender-leaved iceplant (Mesembryanthemum nodiflorum), and holly-leafed cherry (Prunus ilicifolia). Although rats do not eat giant coreopsis (Coreopsis gigantean) as mice do, rats and mice both employ this largeleaved plant as shelter and cover and so may compete for it. Direct predation of rats upon mice is 
208 also a consideration: rats on Anacapa prey on mouse pups, as well as on mice caught in traps

209 (Collins et al., 1979).

210 If rats were a factor in mouse evolution on Anacapa, it would be interesting to evaluate

211 mouse morphology after the rat eradication in 2001-2002. Such future research might sample

212 Anacapa mice periodically (perhaps every 5-15 years) and begin ongoing analysis after perhaps

$21320-30$ years. If mice were generally getting bigger again it would further support the hypothesis

214 of competition with and/or predation by rats as a proximate cause of mouse evolution on Anacapa

215 Island.

216 Acknowledgments

217 We gratefully thank the museums that provided us access to collections and related

218 support, especially Field Museum, Santa Barbara Museum of Natural History, and Natural

219 History Museum of Los Angeles County. We thank Island Conservation for specimens. We thank

220 Larry Heaney, Bill Stanley, Bruce Patterson, John Phelps, Paul Collins, Kate Faulkner, Cathy

221 Schwemm, Dirk Rodriguez, and Bernie Tershy for advice. DB thanks Melissa Trombley-Byrn

222 and ORWP thanks Valerie Morrow for their personal support. This work was partially supported

223 by National Science Foundation Grant CHE 0629174. 
Literature Cited

AFIFI, A., V. A. CLARK, AND S. MAY. 2004. Computer-Aided Multivariate Analysis, 4th ed. Boca Raton, FL: Chapman and Hall/CRC.

AFIFI, A. A. and V. A. CLARK. 1997. Computer-Aided Multivariate Analysis. Chapman and Hall, London, 3rd ed.

BERRY, R. J. 1964. The evolution of an island population of the house mouse. Evolution 18: $468-483$.

BERRY, R. J., M. E. JAKOBSON, AND J. PETERS. 1978. The house mice of the Faroe islands: a study in microdifferentiation. Journal of Zoology London 185: 573-592.

BROWN, M. B. AND A. B. FORSYTHE. 1974. Robust tests for the equality of variances. Journal of the American Statistical Association 69: 364-367.

CASE, T. J. 1978. A General Explanation for Insular Body Size Trends in Terrestrial Vertebrates. Ecology 59:1-18.

CLARKE, W. E. 1904. On some forms of Mus musculus, Linnaeus, with description of a new subspecies from the Faroe islands. Proceedings of the Physical Society of Edinburgh 15: 160167.

COLLINS, P. W. AND S. B. GEORGE. 1990. Systematics and taxonomy of island and mainland populations of western harvest mice (Reithrodontomys megalotis) in southern California.

Contributions in Science, Natural History Museum of Los Angeles County 420:1-26.

COLLINS, P. W., J. STORRER, AND K. RINDLAUB. 1979. XI. Vertebrate zoology: biology of the deer mouse, pp, 11.1-11.74 in A Natural Resources Study of the Channel Islands National Park, California, edited by D.M. Power. Final Technical Report to the U.S. National Park Service. Washington D.C. 
DEBLASE, A. F. AND R. E. MARTIN. 1974. A Manual of Mammalogy. Wm. C. Brown Co.,

Dubuque.

DOBZHANSKY, T. 1937. Genetics and the Origin of Species. Columbia University Press, New York.

DROST, C. A., AND G. M. FELLERS. 1991. Density cycles in an island population of deer mice, Peromyscus maniculatus. Oikos 60:351-364.

ENDLER, J. A. 1980. Natural selection on color patterns in Poecilia reticulata. Evolution 34:7691.

ERICKSON, W. A. AND W. L. HALVORSEN. 1990. Ecology and control of the roof rat (Rattus rattus) in Channel islands National Park. Technical Report No. 38 to the National Park Service. FOSTER, B. F. 1964. Evolution of mammals on islands. Nature 202: 234.

GINGERICH, P. D. 1993. Quantification and comparison of wvolutionary rates. American Journal of Science 293-A:453-478.GLEASON, D. 1958. The Islands and Ports of California. Devin-Adair, New York.

GRANT, P. R., AND B. R. GRANT. 1995. Predicting microevolutionary responses to directional selection on heritable variation. Evolution 49:241-251.

GRANT, P. R., AND B. R. GRANT . 2002. Unpredictable evolution in a 30-year study of Darwin's finches. Science 296:707-711.

HAIRSTON, N. G. JR., AND W. E. WALTON. 1986. Rapid evolution of a life history trait. PNAS 83:4831-4833.

HALDANE, J. B. S. 1949 Suggestions as to quantitative measurement of rates of evolution. Evolution 3: 51-56. 
HEANEY, L. R. 1978. Island area and body size of insular mammals: evidence from the tricolored squirrel (Callosciurus prevosti) of southeast Asia. Evolution 32: 29-44.

HENDRY, A. P. AND M. T. KINNISON. 1999. Prospective: The pace of modern life: Measuring rates of contemporary microevolution. Evolution 53: 1637-1653.

HENDRY, A. P. , T. J. FARRUGIA, AND M. T. KINNISON. 2007. Human influences on rates of phenotypic change in wild animal populations. Molecular Ecology 17:20-29. Supplemental online data accessed 2/7/15 at http://onlinelibrary.wiley.com/doi/10.1111/j.1365294X.2007.03428.x/suppinfo.

HOLM, S. 1979. A simple sequentially rejective multiple test procedure. Scandinavian Journal of Statistics 6: 65-70.

HUXLEY, J. S. 1942. Evolution, the Modern Synthesis. London, Allen and Unwin.

LAWLOR, T. E., 1982. The evolution of body size in mammals: evidence from insular populations in Mexico. American Naturalalist 119:60.

LOMOLINO, M. V., 1985. Body size of mammals on islands: the island rule revisited. American Naturalalist 125: 310.

MAYR, E. 1963. Animal Species and Evolution. Harvard University Press, Cambridge, Massachusetts, 797pp.

MILLIEN, V. 2006. Morphological evolution is accelerated among island mammals.PloS Biology 4:e321.

MILLIEN, V. 2011. Mammals evolve faster on smaller islands. Evolution 65:1935-1944. MILLIEN, V. AND J. DAMUTH. 2004. Climate change and size evolution in an island rodent species: new perspectives on the island rule. Evolution 58 (6), 1353-1360. 
MORAN, M. D. 2003. Arguments for rejecting the sequential Bonferroni in ecological studies.

Oikos 100-2: 403-405.

PATTON, J. L., S. Y. YANG AND P. MYERS. 1975. Genetic and morphological divergence among introduced rat populations (Rattus rattus) of the Galapagos archipelago, Equador. Systematic Zoology 24: 296-310.

PERGAMS, O. R. W. AND M. V. ASHLEY. 1999. Rapid morphological change in Channel island deer mice. Evolution 53: 1573-1581.

PERGAMS, O. R. W. AND M. V. ASHLEY. 2000. California Island deer mice: genetics, morphometrics, and evolution. In: Browne DR, Mitchell KL, Chaney HW, editors. Proceedings of the Fifth California Islands Symposium: 29 March to 1 April 1999. Santa Barbara, CA: Santa Barbara Mus Nat Hist. pp. 278-288.

PERGAMS, O. R. W., R. C. LACY, AND M. V. ASHLEY. 2000. Conservation and management of Anacapa Island deer mice. Conservation Biology 14:819-832.

PERGAMS, O. R. W. AND M. V. ASHLEY. 2001. Microevolution in island rodents. Genetica $112 / 113: 245-256$

PERGAMS, O. R. W., W. M. BARNES, and D. NYBERG. 2003. Rapid change of mouse mitochondrial DNA. Nature 423, 397.

PERGAMS, O. R. W. AND R. C. LACY. 2007. Rapid morphological and genetic change in Chicago-area Peromyscus. Molecular Ecology 17:450-463.

PERGAMS, O. R. W. AND P. KAREIVA. 2009. Support services: A focus on genetic diversity. In: Levin SA, Carpenter SR, Godfray HCJ, Kinzig AP, Loreau M, editors. The Princeton Guide to Ecology. Princeton: Princeton University Press. 
313 PERGAMS, O. R. W. AND J. L. LAWLER. 2009. Recent and widespread rapid morphological

314 change in rodents. PLoS One: $\underline{\text { http://dx.plos.org/10.1371/journal.pone.0006452. }}$

315 REZNICK, D. N., R H. SHAW, R H. RODD, AND R. G. SHAW. 1997. Evaluation of the rate of

316 evolution in natural populations of guppies (Poecilia reticulata). Science 275: 1934-1937.

317 SMITH, T. B., L. A. FREED, J. K. LEPSON, J. H. CAROTHERS. 1995. Evolutionary

318 consequences of extinctions in populations of a Hawaiian honeycreeper. Conservation Biology, 9,

$319 \quad 107-113$.

320 SPSS. 1998. SYSTAT 8.0 for Windows (computer program). SPSS, Inc., Chicago, Illinois. 


\section{Table $\mathbf{1}$ (on next page)}

Table 1.

Test of significant differences between time classes 1940 and 1975-2000. Levene's test was performed to determine equality of variances. Depending on results, the appropriate $t$-test was performed to test significance of differences of means between time classes. NND means traits were not normally distributed and non-parametric Kruskal-Wallis $H$ test were performed. ND means traits were normally distributed. Traits with significant changes are shaded. 


\begin{tabular}{|c|c|c|c|c|c|c|c|}
\hline & \multicolumn{2}{|c|}{ Levene's Statistic } & \multicolumn{3}{|c|}{ Independent Samples $t$-test } & \multicolumn{2}{|c|}{ Kruskal-Wallis $H$} \\
\hline TRAIT & $\mathrm{F}$ & Sig. & $\mathrm{t}$ & $\mathrm{df}$ & Sig. & $\mathrm{H}$ & Sig. \\
\hline TOT & 0.312 & 0.580 & -1.207 & 36 & 0.235 & ND & ND \\
\hline TAIL & 0.994 & 0.325 & -0.791 & 36 & 0.434 & ND & ND \\
\hline $\mathrm{HF}$ & 0.008 & 0.931 & -1.053 & 36 & 0.299 & ND & ND \\
\hline EAR & 8.329 & 0.007 & 0.603 & 34.786 & 0.551 & ND & ND \\
\hline ONL & 0.108 & 0.743 & -2.803 & 49 & 0.007 & ND & ND \\
\hline BR & 0.589 & 0.446 & -2.582 & 54 & 0.013 & ND & ND \\
\hline ZB & 0.543 & 0.465 & -3.013 & 41 & 0.004 & ND & ND \\
\hline IB & 0.428 & 0.516 & -2.634 & 56 & 0.011 & ND & ND \\
\hline BB & 0.496 & 0.485 & -3.2 & 44 & 0.003 & ND & ND \\
\hline LPN & 0.209 & 0.650 & -3.28 & 48 & 0.002 & ND & ND \\
\hline LIF & 0.828 & 0.367 & -2.417 & 52 & 0.019 & ND & ND \\
\hline $\mathrm{AL}$ & NND & NND & NND & NND & NND & 6.666 & 0.010 \\
\hline DBC & 3.643 & 0.063 & -3.042 & 40 & 0.004 & ND & ND \\
\hline GL & 0.015 & 0.904 & -2.518 & 43 & 0.016 & ND & ND \\
\hline LBC & 0.049 & 0.826 & -3.041 & 43 & 0.004 & ND & ND \\
\hline
\end{tabular}


Table 2 (on next page)

Calculation of Amount and Rate of Evolutionary Change.

Three generations per year was used to calculate haldanes (Erickson and Halvorsen 1990).

Shaded areas indicate significant changes, NS=not significan 


\begin{tabular}{|c|c|c|c|c|c|c|c|c|}
\hline & $\begin{array}{l}1940 \\
\text { Mean }\end{array}$ & SE & $\begin{array}{c}\text { 1975-2000 Mean } \\
\text { (1982.894) }\end{array}$ & SE & Response & $\%$ Change & darwins & *haldanes \\
\hline ZB & 19.15 & 0.58 & 20.78 & 0.25 & 1.64 & 7.87 & 1912 & 0.14498 \\
\hline GL & 38.47 & 1.19 & 41.73 & 0.65 & 3.25 & 7.79 & 1892 & 0.06000 \\
\hline IB & 5.68 & 0.11 & 5.97 & 0.05 & 0.30 & 4.95 & 1183 & 0.43255 \\
\hline BB & 15.23 & 0.32 & 16.22 & 0.14 & 0.99 & 6.11 & 1470 & 0.19225 \\
\hline LPN & 22.23 & 0.82 & 24.82 & 0.36 & 2.59 & 10.43 & 2567 & 0.12688 \\
\hline LBC & 27.58 & 0.80 & 29.99 & 0.38 & 2.41 & 8.04 & 1953 & 0.09808 \\
\hline LIF & 6.95 & 0.31 & 7.59 & 0.11 & 0.65 & 8.51 & 2074 & 0.32281 \\
\hline $\mathrm{AL}$ & 6.44 & 0.11 & 6.64 & 0.04 & 0.20 & 3.06 & 724 & 0.29203 \\
\hline $\mathrm{DBC}$ & 13.32 & 0.23 & 13.95 & 0.09 & 0.63 & 4.55 & 1084 & 0.20862 \\
\hline TOT & $N S$ & $N S$ & $N S$ & $N S$ & $N S$ & $N S$ & $N S$ & $N S$ \\
\hline TAIL & $N S$ & $N S$ & $N S$ & $N S$ & $N S$ & $N S$ & $N S$ & $N S$ \\
\hline HIND & $N S$ & $N S$ & $N S$ & $N S$ & $N S$ & $N S$ & $N S$ & $N S$ \\
\hline EAR & $N S$ & $N S$ & $N S$ & $N S$ & $N S$ & $N S$ & $N S$ & $N S$ \\
\hline
\end{tabular}




\section{Table 3 (on next page)}

Linear regressions of the traits of the specimens with the year each specimen was collected.

All 11 traits fit significantly. 


$\begin{array}{crrrrrrrrrrr}\text { Multiple } & \text { ONL } & \text { BR } & \text { ZB } & \text { GL } & \text { IB } & \text { BB } & \text { LPN } & \text { LBC } & \text { LIF } & \text { AL } & \text { DBC } \\ R 2 & 0.182 & 0.147 & 0.189 & 0.188 & 0.195 & 0.226 & 0.210 & 0.235 & 0.132 & 0.129 & 0.142 \\ N & 51 & 56 & 43 & 45 & 58 & 46 & 50 & 45 & 54 & 58 & 42 \\ F & 12.136 & 10.505 & 10.787 & 11.179 & 14.836 & 14.118 & 14.059 & 14.531 & 9.030 & 9.445 & 7.796 \\ \mathrm{P} & 0.001 & 0.002 & 0.002 & 0.002 & <0.0005 & 0.001 & <0.0005 & <0.0005 & 0.004 & 0.003 & 0.008 \\ & - & - & - & - & & - & & & - & - & - \\ \text { constant } & 70.193 & 22.431 & 50.736 & 130.835 & -10.938 & 30.063 & -94.951 & -88.491 & 24.662 & 5.719 & 10.143 \\ 2 & & & & & & & & & & & \end{array}$




\section{1}

Linear regressions comparing each measurement of each trait with the year in which the specimen was collected.

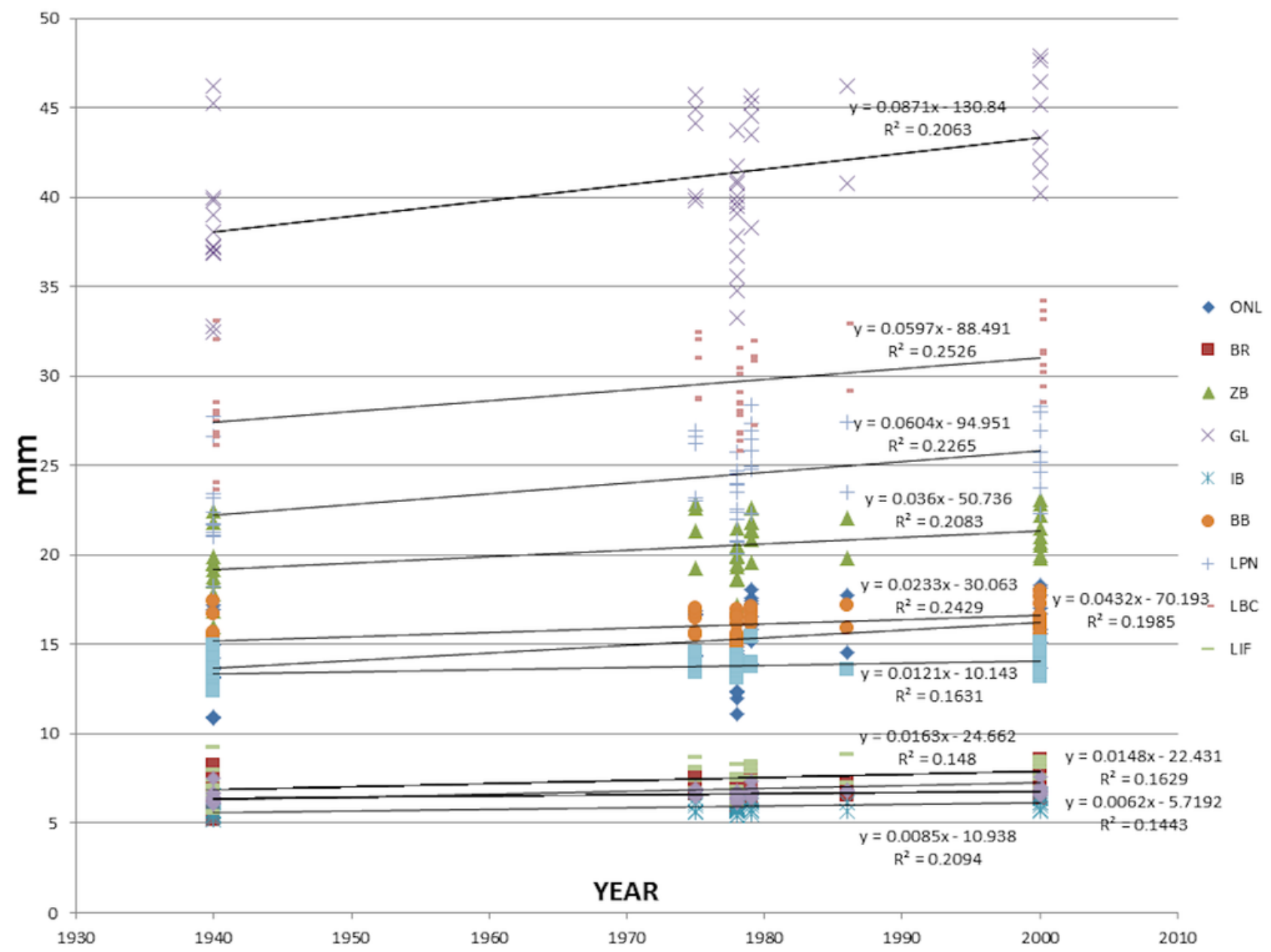

